\title{
ENCRUZILHADA DE SABERES EM TEMPOS DE CÓLERA: currículo decolonial e pedagogias da escrevivência
}

Fabiana de Lima Peixoto

Resumo

Com a entrada de novos sujeitos do conhecimento na universidade pública brasileira, por meio de políticas de cotas, foram exigidas reformas paradigmáticas na organização e no currículo do ensino superior, a partir de perspectivas epistemológicas pluriversais. Assim, dialogando com perspectivas teórico-metodológicas que estabelecem diálogo entre decolonialidade e educação, o objetivo principal deste artigo é a reflexão crítica sobre cursos de formação docente em universidade pública da Bahia que apostam na pluriversalidade epistêmica, no ensino interprofissional e na interdisciplinaridade, abrindo trincheira para a experimentação de pedagogias decoloniais. A arquitetura curricular da UF constituiu-se, entre 2015 e 2019, em uma perspectiva integradora de saberes, práticas e segmentos do ensino superior (graduação e pós-graduação), organizados por sistema de ciclos, compostos por fases sucessivas e articuladas de formação, responsáveis por intensa flexibilidade na trajetória curricular do estudante de graduação. A partir desse contexto, esse artigo relatará criticamente a atuação de uma intelectual negra na Licenciantura Interdisciplinar de Ciências Humanas e Artes, no que diz respeito à maneira pela qual tem produzido conhecimentos e práticas pedagógicas em torno das relações étnico-raciais, da estética negrodescendente, do racismo, de episteme afro-brasileira.

Palavras-chave: formação docente; currículo decolonial; educação antirracista

\section{CROSSROADS OF KNOWLEDGE IN TIMES OF CHOLERA: decolonial curriculum and escrevivência pedagogies}

\begin{abstract}
With the entry of new subjects of knowledge in the Brazilian public university, through quotation policies, paradigmatic reforms were demanded in the organization and curriculum of higher education, from epistemological multi-universal perspectives. Thus, when reaching reflections in the level of decoloniality and education, the main objective of this article is the critical reflection on teacher training courses at the public university in Bahia that bet on epistemic pluriversality, interprofessional teaching and interdisciplinarity, providing the experimentation of pedagogies decolonial. The curricular architecture of UF was constituted, between 2015 and 2019, in an integrating perspective of knowledge, practices and segments of higher education (undergraduate and graduate), organized by cycle system, composed of successive and articulated training phases, responsible for intense flexibility in the student's training path. From this context, this work will attempt to critically report on the teaching experience of a black intellectual in the Interdisciplinary Bachelor of Human Sciences and Arts, with regard to the way in which she has produced pedagogical knowledge and practices around ethnic-racial relations, of black and descending aesthetics, racism to Brazilian and black epistemes in Brazil.
\end{abstract}

Keywords: teacher training; decolonial curriculum; anti-racist education 


\section{ENCRUCIJADA DE CONOCIMIENTOS EN TIEMPOS DE CÓLERA: currículum descolonial y pedagogias de escrevivência}

\section{Resumen}

Con la entrada de nuevas materias de conocimiento en la universidad pública brasileña, a través de políticas de cotización, se exigieron reformas paradigmáticas en la organización y el plan de estudios de la educación superior, desde perspectivas epistemológicas pluriversales. Por lo tanto, al alcanzar reflexiones en el nivel de descolonialidad y educación, el objetivo principal de este artículo es la reflexión crítica sobre los cursos de formación docente en la universidad pública de Bahía que apuestan por la pluriversidad epistémica, la enseñanza interprofesional y la interdisciplinariedad, proporcionando la experimentación de las pedagogías decolonial. La arquitectura curricular de la UF se constituyó, entre 2015 y 2019, en una perspectiva integradora de conocimientos, prácticas y segmentos de educación superior (pregrado y posgrado), organizada por sistema de ciclo, compuesta de fases de formación sucesivas y articuladas, responsables de intensa flexibilidad en el camino de formación del alumno. Desde este contexto, este trabajo intentará informar críticamente sobre la experiencia docente de un intelectual negro en el Bachillerato Interdisciplinario de Ciencias y Artes Humanas, con respecto a la forma en que ha producido conocimiento y prácticas pedagógicas en torno a las relaciones étnico-raciales, de estética negra y descendente, racismo a los epistemes brasileños y negros en Brasil.

Palabras clave: formación del profesorado; currículum descolonial; educación antirracista

\section{DESCOLONIZANDO SABERES: ESCREVIVÊNCIA E SUAS PEDAGOGIAS}

a estrada épó... ê, mãe!
ali
mantra
o que sou
soul
soul

(Thank you, Exu! Lande Onawale)

Estar na encruzilhada faz-nos deslizar entre a incerteza do caos e a complexidade de que há múltiplos caminhos possíveis. Lugar legado, nas vias de Exu, pelos antepassados negro-africanos forçadamente transmigrados que me trouxeram até os tempos de cólera de 2020, quando ser uma intelectual negra ${ }^{1}$ na academia requer navalha afiada, experiência de profundidade teórico-crítica, em oposição à realidade social que tem imposto superficialidade e uma avassaladora digitalização global da economia de mercado. É nesse contexto sócio-político que ingresso na vida acadêmica enquanto docente, em 2015, para trabalhar em uma universidade baiana cujo projeto institucional foi desenvolvido para o ingresso de estudantes pobres, marcadamente populações negras (incluindo estudantes quilombolas da região), indígenas e trabalhadores da terra.

Conforme demonstrarei nesse artigo, o trabalho na Universidade Federal do Sul da Bahia (UFSB) tem-me trazido, como jamais experimentado anteriormente na vida profissional, um

\footnotetext{
${ }^{1}$ Intelectual Negra é utilizado neste artigo no sentido das reflexões de Nilma Lino Gomes acerca do contexto brasileiro da intelectualidade negra na contemporaneidade, discutido no artigo Intelectuais Negros e produção do conhecimento: algumas reflexões sobre a sociedade brasileira (In: SANTOS, B. S., MENESES, M. P. [org]. Epistemologias do Sul. São Paulo: Cortez, 2011) e da perspectiva traçada por bell hooks, no artigo Intelectuais Negras (Revista Estudos feministas, n. 2, 1995. v. 3, 1995).
} 
aprofundamento das questões que envolvem educação das relações étnico-raciais ${ }^{2}$ em perspectiva interepistêmica ${ }^{3}$, da promoção dos direitos humanos, do combate ao racismo, tendo em vista a experiência com formas diferenciadas de pensar e praticar o currículo de cursos de ensino superior, especialmente na formação docente. Essa experiência recente tem-me levado a considerar tais questões mais do que imprescindíveis para exercer as atividades acadêmicas, incluindo docência, pesquisa, extensão e criação, a partir de uma rede de abordagens político-pedagógicas que envolvem descolonização do currículo, rompimento com paradigmas contínuos e lineares de organização do conhecimento e abertura da universidade para a sociedade, incluindo diálogo produtivo - e que se deseja desierarquizado — com movimentos sociais, instituições de educação básica, comunidades e mestres tradicionais, entre outros espaços de suma importância para o processo formativo do estudante de graduação, sobretudo do profissional da carreira docente nas áreas de Ciências Humanas e Artes.

De acordo com a análise de Nilma Lino Gomes (2011; 2012; 2017), a entrada de novos sujeitos do conhecimento na universidade pública brasileira pelas políticas de cotas, levando em consideração sobretudo estudantes, mas também docentes, tem exigido mudanças no currículo e, por conseguinte, nas práticas de ensinar e aprender, que considerem o contexto de epistemicídio próprio da colonialidade que se constituiu na dinâmica da nossa historicidade enquanto nação sul-americana. Boaventura de Sousa Santos (2000), ao refletir sobre o modus operandi do sistema colonial, demonstra como o apagamento da legitimidade de formas de conhecimento de grupos subjugados durante e depois do colonialismo é a mais eficaz e duradoura forma de dominação étnico-racial produzida pela expansão colonial europeia. Na formulação teórica de Santos, o epistemicídio nas nações modernas se inicia com o projeto econômico de expansão territorial europeu, mas se estende para muito além dele. De um traço da ocupação europeia em países não europeus, acabou por se perpetuar como traço mesmo de dominação na modernidade, fosse através do capitalismo ou do socialismo. Nesse sentido, a violência inerente ao silenciamento da episteme de grupos subalternizados tem-se tornado, portanto, prática intelectual corrente na tradição euro-ocidental hegemônica.

A partir de lógica descolonizadora de saberes e práticas, pensar junto com outros colegas nova organização curricular e práticas de formação docente na UFSB, em Artes e Ciências Humanas e Sociais, tem-me permitido o diálogo com pedagogias decoloniais, as quais tensionam com a organização curricular mais comum, que compreende os saberes acadêmicos enquanto rol de conteúdos sobrepostos em sequência linear, levando ao aprendizado de habilidades profissionais

\footnotetext{
${ }^{2}$ Raça, neste artigo, bem como suas derivações racial, racismo não são utilizados como categoria biológica consagrada pelo cientificismo do século XIX, mas como categoria analítica que objetiva tratar do caso específico brasileiro, onde a ideia de raça funciona como operador ideológico delimitador de espaços sociais e formulador de atitudes de exclusão. Dentro de tal perspectiva analítica, utilizar uma palavra corrente no contexto social e que carrega em si critérios de discriminação possibilita observar, de maneira crítica, os pilares que fundamentam ideologias racistas. Por isso, opto por usar raça e/ou racial aliado à categoria de etnia e suas derivações, indistintamente.

3 (Inter)epistemicidade implica, na perspectiva de Boaventura de Sousa Santos, Nilma Lino Gomes, entre outra/os que têm pensado a decolonialidade no campo da educação, praticar a importância da desierarquização de distintos saberes dentro das instituições educacionais, possibilitando uma perspectiva curricular e prática que tensione com o eurocentrismo, abrindo-se a outras epistemes historicamente silenciadas no meio acadêmico. $\mathrm{Na}$ trilha das reflexões teóricas de Foucault (1987), episteme se performa enquanto condições discursivas que constituem uma epistemologia, ou seja, o conjunto de relações epistemológicas entre as ciências humanas. A proposta foucaultiana de narrar a história das ciências humanas através de perspectiva descentralizada e descontínua não só levou à compreensão do homem como problema para o saber humano desde o século XVI europeu, como sobretudo tem possibilitado, desde então, o delineamento epistemológico de humanidades que não se restringem ao parâmetro europeu-ocidental, princípio teórico-metodológico donde provém, em tensão, o termo interepistemicidade.
} 
teoricamente esperadas para o/a professor/a em formação, desconsiderando múltiplas epistemologias que interagem num contexto sócio-histórico intercultural, marcado pela desigualdade social. Ao trazer para o espaço acadêmico formas de (en)sinar e aprender negroafricanas e indígenas bem como a produção de conhecimentos dos movimentos sociais, subvertese determinada perspectiva curricular monocultural e hierarquizadora dos saberes.

Trazer para o campo da produção de conhecimentos a dimensão dos saberes é a possibilidade de se contemplar a subjetividade — individual e coletiva — do produtor ou transmissor de conhecimentos, na medida em que, a partir de estudos das culturas populares, dos movimentos sociais, das teorias pós-coloniais e decoloniais ${ }^{4}$, tem-se questionado a centralidade do conhecimento científico de modelo europeu em relação a formas de conhecer de civilizações não europeias no meio acadêmico-universitário, espaço social privilegiado politicamente no tocante à produção de saberes considerados válidos em determinada sociedade. Dessa forma, em diálogo com a reflexão de Nilma Lino Gomes, na obra Movimento Negro Educador: saberes construídos nas lutas por emancipação, opto nesse artigo por não distinguir os termos saber e conhecimento. Nas palavras da autora:

A separação entre conhecimento e saber, tal como a vivemos na escola e na produção científica educacional, é fruto da interpretação da ciência moderna, que marca o campo da educação. E é justamente a leitura crítica de como o conhecimento científico, fruto da ciência moderna, tornou-se a forma hegemônica de saber valorizada no campo da educação e, por conseguinte, nos currículos escolares, que me permite indagar e tentar ir além da distinção (quase unânime no campo educacional) entre conhecimento e saber. (GOMES, 2017, p. 66)

Acompanhando a ruptura com uma lógica monocultural e eurocêntrica de lidar com a produção de conhecimentos, pedagogia decolonial é aqui compreendida enquanto uma abordagem teórico-prática que, apostando numa mudança paradigmática no campo da educação, promove a diversidade epistêmica, ao contemplar racionalidades de povos subalternizados, e a socialização de seus saberes, transformando o espaço universitário em um território de diálogo pluriversal ${ }^{5}$, porque marcado pelo encontro (dis)tenso entre diversas epistemologias e formas de ensinar e aprender afropluriversadas.

\footnotetext{
${ }^{4}$ Os termos decolonial, decolonialidade, descolonizados, pós-coloniais, apesar das variações conceituais entre eles, congregam epistemologicamente uma disposição de enfrentamento das relações coloniais de poder que constituem o capitalismo moderno de modelo ocidental-europeu desde o século XVI, sustentadas pela classificação e domínio étnico-racial das sociedades colonizadas, bem como pela criação de uma subjetividade responsável por formalizar um modo de produzir conhecimento de orientação eurocêntrica, que se hegemoniza como a única possível, tornando-se, portanto, uma perspectiva cognitiva de domínio e reprodução da colonialidade. (QUIJANO, 2010; SANTOS, 2010; GOMES, 2010, 2017; GROSFOGUEL, 2010; MALDONADO-TORRES, 2010).

${ }^{5}$ Pluriversalidade epistêmica é utilizada, nesse artigo, em diálogo com as reflexões teórico-metodológicas de Walter Mignolo (2006), quando desafia a geopolítica do conhecimento eurocêntrico a partir da hegemonia da racionalidade científica pela proposição de outro paradigma para a produção de saberes que contemple formas de conhecimento cuja racionalidade tem sido historicamente negada em nome da ciência; e de Renato Noguera (2012) quando, empenhado em (re)pensar a filosofia africana através de abordagem que ele nomeia afroperspectivista, concebe a educação como um exercício policêntrico, intercultural e perspectivista. Guardadas as especificidades de cada autor, suas construções teórico-críticas dialogam com discussões do Sul Global que relacionam colonialidade (do poder, do saber, do ser) e educação.
} 
Como neste artigo me dedicarei a analisar de que maneira saberes africanodescendentes ${ }^{6}$ têm circulado em cursos de formação docente da Universidade onde leciono, a partir de organização curricular e de práticas diferenciadas, a noção de educação descolonizadora possibilita dialogar com o neologismo escrevivência, proposto pela escritora negra Conceição Evaristo (2007) ao explicar os sentidos existencial e político de sua produção literária. Essa palavra tem, no decorrer do tempo, se transformado em conceito para escritoras e intelectuais negras, quando traduz uma ética decolonial comprometida com epistemologias e formas de ensinar e aprender afropluriversais.

Enegrecendo a questão, em ensaio memorial que narra a consciência política da sua escrita ficcional e poética, Conceição Evaristo assume a primeira pessoa como dicção emancipatória no mundo, que acaba por transformar a escrita em uma extensão do corpo-memória da mulher negra. Dessa forma, o "eu", no caso da memória de mulheres negras, jamais pode ser lido como a expressão de um corpo individualizado. Ao contrário, em diálogo tenso com determinada lógica colonial que subalterniza o corpo-memória negro e feminino, esse "eu" se coletiviza ao se narrar, pois partilha experiência de vida das mulheres negras em uma sociedade de mentalidade colonial, racista e sexista.

$\mathrm{Na}$ origem da minha escrita ouço os gritos, os chamados das vizinhas debruçadas sobre as janelas, ou nos vãos das portas contando em voz alta uma para outras as suas mazelas, assim como as suas alegrias. Como ouvi conversas de mulheres! Falar e ouvir entre nós era talvez a única defesa, o único remédio que possuíamos. Venho de uma família em que as mulheres, mesmo não estando totalmente livres de uma dominação machista, primeira a dos patrões, depois a dos homens seus familiares, raramente se permitiam fragilizar. Como "cabeça" da família, elas construíam um mundo próprio, muitas vezes distantes e independentes de seus homens e, mormente, para apoiá-los depois. Talvez por isso tantas personagens femininas em meus poemas e em minhas narrativas? Pergunto sobre isto, não afirmo. (EVARISTO, 2007, p. 20)

O questionamento da escritora coletiviza saberes criados a partir de um corpo-memória de muitas vozes, muitas mulheres, portanto também de uma escrita oralizada, em tensão tecnológica e política com a cultura letrada do ocidente. Conceição, muito mais do que criar um mito de origem para o próprio fazer artístico, batiza uma pedagogia afropluriversal que extrapola os limites da literatura e ecoa em diapasão no pensamento negro brasileiro. Por isso, em termos de pesquisa, tenho-me dedicado a compreender criticamente, a partir da prática nos cursos de formação docente da UFSB, o que tenho chamado de pedagogias da escrevivência, ou seja, formas de ensinar e aprender construídas a contrapelo da lógica monoepistêmica e monocultural do ocidente, criadas a partir do lastro da memória social e racial de seus criadores (mestres tradicionais, intelectuais de movimentos negros, líderes ativistas negros, comunidades negrodescendentes), comprometidos com a memória africana no Brasil enquanto contra-narrativas (intelectuais, epistêmicas, estéticas, performáticas) às relações coloniais, racistas e sexistas de poder.

Ademais, nos parágrafos finais do ensaio, Evaristo situa no corpo das mulheres negras o lugar privilegiado a partir do qual são produzidos saberes, oralizados e letrados, acerca de

\footnotetext{
${ }^{6}$ Embora reconheça diferentes apreensões teórico-práticas elaboradas por intelectuais e ativistas negros/as em torno do uso dos termos negro, afro-brasileiro, afrodescendente, negro-brasileiro, negrodescendente, africanodescendente, entre outros semelhantes, opto nesse artigo por usá-los indistintamente, reservando outro momento para analisar as consequências metodológicas e políticas de cada um de seus usos.
} 
existências capturadas pelo racismo estrutural, pela subalternização de gênero, pela colonialidade, desafiando o adestramento dos corpos que essa malha opressora encerra:

E retomando a imagem da escrita diferencial de minha mãe, que surge marcada por um comprometimento de traços e corpo (o dela e nossos) e ainda a um Diário escrito por ela, volto ao gesto em que ela escrevia o sol na terra e imponho a mim mesma uma pergunta. O que levaria determinadas mulheres, nascidas e criadas em ambientes não letrados, e quando muito, semi-alfabetizados, a romperem com a passividade da leitura e buscarem o movimento da escrita?

Tento responder. Talvez, estas mulheres (como eu) tenham percebido que se o ato de ler oferece a apreensão do mundo, o de escrever ultrapassa os limites de uma percepção da vida. Escrever pressupõe um dinamismo próprio do sujeito da escrita, proporcionando-lhe a sua auto-inscrição no interior do mundo. E, em se tratando de um ato empreendido por mulheres negras, que historicamente transitam por espaços culturais diferenciados dos lugares ocupados pela cultura das elites, escrever adquire um sentido de insubordinação. Insubordinação que pode se evidenciar, muitas vezes, desde uma escrita que fere "as normas cultas" da língua, caso exemplar o de Carolina Maria de Jesus, como também pela escolha da matéria narrada. A nossa escrevivência não pode ser lida como histórias para "ninar os da casa grande" e sim para incomodá-los em seus sonos injustos. (EVARISTO, 2007, p. 20)

A escrevivência de Evaristo é gesto, movimento de corpo, enunciado pelo riscado de sua mãe no quintal para chamar o sol. E é gesto insubordinado. Por extensão, o corpo e a insubordinação à lógica de produção de saberes eurocêntrica também marcam o que venho chamando de pedagogias da escrevivência, sempre territorializadas e desenvolvidas a partir de corporalidades cujas formas de ensinar e aprender requerem elaboração cognitiva que não passa pela primazia da lógica racional, conforme veremos mais adiante. $\mathrm{O}$ aprendizado de corpo inteiro das pedagogias da escrevivência tem demonstrado ser uma prática emancipatória em educação, porque é marcada pela positivação do corpo negro no processo de construções identitárias e produção de conhecimentos. A intelectual negra Nilma Lino Gomes (2017) elabora reflexão em torno do corpo negro regulado e do corpo negro emancipado, na medida em que a educação escolar tem sido um dos principais espaços da socialização de discursos reguladores sobre o corpo negro:

No Brasil, o corpo negro ganha visibilidade social na tensão entre adaptar-se, revoltar-se ou superar o pensamento racista que o toma por erótico, exótico e violento. Essa superação se dá mediante a publicização da questão racial como um direito, via práticas, projetos, ações políticas, cobrança do Estado e do mundo privado da presença da população negra na mídia, nos cursos superiores, na política, nos lugares de poder e decisão, na moda, na arte, entre outros. (GOMES, 2017, p. 94)

(En)sinar esse corpo racializado em cursos superiores de formação docente, levando-o a se colocar na sina de epistemologias afropluversais, significa se aventurar na produção de saberes descolonizadores a partir de pedagogias que surgem do lastro da memória — individual à coletiva — da experiência com saberes tradicionais africanos recriados na história social brasileira e com o racismo e sexismo. Trata-se, como no caso do termo criado pela escritora Conceição Evaristo, de um "eu" coletivizado em formas de ensinar e aprender não hegemônicas em universidade pública 
brasileira. A minha própria reflexão crítica nesse artigo acadêmico também se compromete com uma inscrição intelectual que, do "eu" ao "nós", se compreende emancipatória.

Nesse sentido, biografar-me profissionalmente adquire o sentido de colocar a minha trajetória aprendente - na perspectiva de professora e intelectual negra - como objeto de investigação crítica acerca das possibilidades de uma formação docente comprometida com perspectiva epistemológica antirracista, interdisciplinar, interprofissional, intercultural e interepistêmica.

\title{
FORMAÇÃO DOCENTE PLURIVERSAL PARA UMA VIDA DECENTE NO SUL DA BAHIA
}

\author{
depois dos lares loteados \\ pelas botas da violência \\ e dos empregos cotizados \\ para servir às aparências \\ depois dos elencos rateados \\ nos cabendo a subserviência \\ é tempo de outros papéis \\ e-por que não? - de anéis... \\ (Acerto de Cotas. Lande Onawale)
}

Ter-me tornado em 2015 docente em universidade pública brasileira, mais precisamente na última pensada por meio do Programa de Apoio a Planos de Reestruturação e Expansão das Universidades Federais (REUNI), tem significado lidar com a agudização do desmonte de políticas públicas que, no decorrer da última década e meia, buscaram, pelas leis, diretrizes e ações, a promoção de igualdade social, racial e epistêmica, descolonizando o currículo do ensino superior e da escola básica no Brasil com relação ao direcionamento eurocêntrico, à mentalidade colonial e ao apagamento da história, cultura, conhecimentos e saberes africanos, afro-brasileiros e indígenas.

Nessa perspectiva teórico-metodológica, interessa compreender criticamente, a partir de então, uma organização curricular que se quis, visível no projeto inicial da UFSB, aberta, pelo baixo índice de pré-requisitos entre os componentes curriculares dos cursos iniciais da Universidade (Bacharelados e Licenciaturas Interdisciplinares); de percurso interdisciplinar, pela obrigatoriedade de os estudantes cumprirem créditos nas quatro grandes áreas oferecidas - Artes, Humanidades, Ciências da Natureza, Saúde - e cursarem juntos componentes curriculares da chamada Formação Geral (FG); interepistêmica, pela construção de diálogo com saberes afro-indígenas, de movimentos sociais e de comunidades tradicionais. Nesse sentido, compreender como as Licenciaturas Interdisciplinares (LI) da UFSB têm construído o currículo de formação docente, sobretudo nas áreas de Ciências Humanas e Artes, abre-se como possibilidade de discutir criticamente a organização do conhecimento no ensino superior brasileiro, a partir de epistemologias e pedagogias que se desenvolvem em meio a relações de poder desiguais nos âmbitos sociais e acadêmico.

Tais percursos curriculares levam a reconhecer a história e saberes acumulados pela população negra e pelos movimentos políticos negros como parte do saber legítimo a ser estudado no ensino superior brasileiro e, como consequência, da formação do profissional docente da escola básica. Ao lado de organizações curriculares emancipatórias de outras graduações para formação 
docente em universidades públicas brasileiras ${ }^{7}$, o currículo na UFSB, até o ano letivo de 2019, de maneira ampla e especificamente nas áreas de Ciências Humanas e Artes, acaba por questionar um encaminhamento eurocêntrico, disciplinar e monocultural, levando ao diálogo com produção de saberes, práticas sociais e conhecimentos dos povos africano-descendentes e indígenas.

Até 2019, a arquitetura curricular da UFSB se constituiu em perspectiva integradora de saberes, práticas e segmentos do ensino superior, organizada por regime de ciclos, composto por fases sucessivas e articuladas de formação, responsáveis por intensa flexibilidade no percurso curricular do estudante, em nível de graduação e pós-graduação. Dessa forma, até 2018, embora houvesse um planejamento para o avançar da integralidade nos cursos de primeiro ciclo, o estudante tinha a possibilidade de, durante o Bacharelado Interdisciplinar (BI) ou a Licenciatura Interdisciplinar $(\mathrm{LI})^{8}$, transitar por diferentes áreas, podendo cursar até duas Áreas de Concentração, que dariam acesso aos cursos profissionais de segundo e de terceiro ciclos?

No âmbito da organização do ano letivo na UFSB em regime quadrimestral, o estudante cursa, no primeiro ano (três quadrimestres), a chamada Formação Geral (FG), composta por componentes curriculares (CC) de afiliação à Universidade, que procuram desenvolver de forma teórico-prática consciência política, num contexto de mundialização da cultura; e criticidade, compromissada com o desenvolvimento regional do Sul da Bahia, a partir de epistemologias contra-hegemônicas e integradoras, por buscarem relacionar território local e global dinamicamente. Fase que leva o estudante não só a experimentar produção de saberes em diferentes áreas de conhecimento acadêmico e não acadêmico, mas sobretudo a ampliar a própria visão de mundo, na perspectiva da complexidade e de uma formação superior cidadã. Também através da FG, o estudante tem acesso à discussão sobre a estrutura, percurso histórico e compreensão política da universidade no mundo ocidental, especialmente no Brasil, a partir dos componentes curriculares (CC) "Universidade e Sociedade"; "Universidade e Desenvolvimento Regional e Nacional"; "Universidade e Contexto Planetário", possibilitando apreensão crítica do próprio ingresso e percurso formativo na graduação. Pontua-se a importância desse rol de CC para a vida acadêmica dos ingressantes, já que em maioria são a primeira geração da família a acessar o ensino superior.

Além desse eixo temático, há componentes curriculares voltados para o conhecimento introdutório das diferentes áreas de conhecimento ${ }^{10}$, para uma perspectiva contextualizada e crítica

\footnotetext{
${ }^{7}$ É importante enfatizar que cursos como a Licenciatura Interdisciplinar (LI) em Estudos Africanos e Afro-Brasileiros e a LI de Ciências Humanas/História da UFMA; a LI Artes da UFRB, bem como os Bacharelados Interdisciplinares (BI) da UFBA, UFRB, UFABC, entre outras universidades, apresentam-se, assim como as LI e os BI da UF, enquanto propostas de reconfiguração curricular em projetos de graduação que se compreendem inclusivos.

8 São cinco as Licenciaturas Interdisciplinares na UF: LI de Ciências Humanas e Sociais e suas tecnologias; LI de Artes e suas tecnologias; LI de Ciências da Natureza e suas tecnologias; LI de Matemática e Computação e suas tecnologias; LI de Linguagens e suas tecnologias.

${ }^{9}$ Entre os anos de 2018 e 2019, inúmeras mudanças nesse modelo de organização curricular têm sido feitas na UFSB, através de uma proposta de reestruturação acadêmica e administrativa, elaborada pela Reitoria da instituição e legitimada em reuniões do Conselho Universitário (CONSUNI) da Universidade. Entre as mudanças, o fim do percurso curricular interdisciplinar e do primeiro ano da formação geral estão em curso. Nesse sentido, as questões referentes ao formato primeiro proposto para a UF, em termos curriculares, acadêmicos e administrativos representarão nesse artigo a memória de uma construção alternativa de organização curricular comprometida com a integração de epistemologias diversas, na perspectiva da ecologia de saberes, práticas e pedagogias no ensino superior. 10 Refiro-me aos CC Campo de Educação: saberes e práticas; Campo das Humanidades: saberes e práticas; Campo das Artes: saberes e práticas; Campo das Ciências: saberes e práticas; Campo da Saúde: saberes e práticas, cursados, obrigatoriamente, pelo estudante na área que deseja prosseguir no trajeto acadêmico de ciclos e, voluntariamente, dois de outros campos de saberes, pelo menos, enquanto componentes curriculares optativos.
} 
das grandes áreas de Linguagens e Matemática ${ }^{11}$ e o CC "Experiências do Sensível", que não é avaliado qualitativamente como os outros, porque tem como principal objetivo, pela via da memória e de práticas artísticas, levar o estudante a (re)ver o seu território de nascença e moradia a partir de um olhar sensível sobre a história familiar, local e regional. Enfatizo a importância desse CC para o docente em formação que consegue, já no primeiro ano da graduação, não só (re)ler a própria história, mas sobretudo se encontrar com práticas de ensino-aprendizagem que desafiam o modelo de ensinar e aprender mais comum da educação brasileira, restrito, quase sempre, ao exercício da razão e ao adestramento disciplinador dos corpos.

Entre os espaços educacionais para a formação docente na UFSB, destaca-se a Rede Anísio Teixeira de Colégios Universitários ${ }^{12}$ (Rede CUNI), na medida em que, por meio de projetos educacionais em parceria com a Secretaria Estadual e Secretarias Municipais de Educação, tem-se tornado espaço privilegiado de troca dialógica entre discentes e docentes da Universidade e das escolas, possibilitando desenvolver reflexão e práticas pedagógicas emancipatórias, incluindo as que implicam educação e diferenças, dentre elas a diferença étnico-racial, importante de ser pensada político-pedagogicamente, tendo em vista a maioria numérica de estudantes negros nas escolas públicas da região e a subjugação colonial dos trabalhadores da terra, traço da tradição coronelista do Sul da Bahia.

Harmonizando-se com o contexto das práticas nas Licenciaturas Interdisciplinares, os cursos e os projetos de formação docente em Ciências Humanas e Sociais e Artes na UFSB têm buscado praticar a noção freireana de autonomia, compreendendo todos os atores das LI como produtores de saberes coletivamente (com)partilhados sobre a docência, a partir de percursos formativos diversos direcionados à prática docente. Nesse processo, professora/es e estudantes das LI têm-se (re)construído continuamente, nos próprios percursos de formação, enquanto sujeitos aprendentes, pois tomam a prática como espécie de laboratório para o desenvolvimento de estratégias político-pedagógicas criativas, transformadoras do cenário educacional.

Devido a esse encaminhamento metodológico, tenho trabalhado ${ }^{13} \mathrm{com}$ a centralidade da autoria em primeira pessoa, na formação inicial e continuada de professora/es, no intuito de se pensar/praticar a formação docente como um enredado coletivo de narradores, para que, a partir da memória/narrativa do sujeito aprendente, cada professor(a) em contínua formação possa se (per)fazer, amadurecendo a reflexão profissional no campo da educação, sem jamais se desconectar da prática.

Dessa forma, outra questão paradigmática nas LI da UFSB é a valorização da dimensão da prática, ou melhor, da inseparabilidade entre teoria e prática na formação docente, tendo em vista

\footnotetext{
${ }^{11}$ Refiro aos CC Língua, Território e Sociedade; Leitura, Escrita e Sociedade; Expressão Oral em Língua Inglesa; Compreensão e Expressão em Língua Inglesa; Matemática e Cotidiano; Perspectivas Matemáticas e Computacionais. 12 A Rede CUNI, inspirada em modelo universitário de Anísio Teixeira, em linhas gerais, é composta por salas da UFSB em escolas de educação básica. Até agora, a partir de negociação com a Secretaria de Educação do Estado da Bahia (SEC-BA), escolas estaduais têm sediado a Rede CUNI. Essa espécie de ocupação do território da educação básica por uma instituição pública de ensino superior acaba por estabelecer relação sistêmica entre discentes e profissionais da Universidade com discentes e profissionais das escolas. Os impactos desse diálogo na formação docente precisam ser escrutinados. Embora esse artigo não se aprofunde nessa análise que se faz necessária, aponta para as possibilidades enriquecedoras desse diálogo para a formação dos estudantes das LI e dos programas de graduação e pós-graduação relacionados à formação docente na UF.

13 Inscrevo-me em primeira pessoa nesse artigo enquanto docente das LI da UFSB e do Curso de Especialização em "Pedagogias das Artes: linguagens artísticas e ação cultural" na mesma instituição; bem como na condição de coordenadora de Subprojeto do Programa de Iniciação à Docência (PIBID/CAPES/UFSB), durante os anos de 2018 e 2019; articuladora de projetos pedagógicos nas escolas parceiras.
} 
o diálogo profícuo com territórios educacionais da região Sul e extremo Sul da Bahia. Dessa forma, ao docente em formação na LI, é possível experimentar potencialidades e limitações da atuação do professor no sistema educacional brasileiro, porque o currículo das LI é marcado pelo diálogo contínuo com a escola básica, por meio do Estágio Supervisionado, cursado pelo licenciando desde o momento em que decide percorrer os componentes curriculares específicos de uma das LI; além da atuação em projetos educacionais da UFSB desenvolvidos em estreita (co)relação com a produção de práticas pedagógicas emancipatórias na escola básica, caso dos espaços dos Colégios Universitários e dos Complexos Integrados de Educação ${ }^{14}$ — que têm sido, desde 2016, arena de diálogo inovador entre Universidade e escola.

Certamente, tais mudanças paradigmáticas no planejamento de cursos de formação docente no ensino superior trouxeram para a minha vida profissional uma enorme ampliação de perspectiva quanto a uma educação comprometida com a epistemodiversidade, com o combate ao racismo, com a promoção dos direitos humanos e com a dignidade dos segmentos populacionais subalternizados na tradição histórica do Brasil, marcada pelas colonialidades do poder e do saber.

Além disso, reposicionar-me enquanto docente e intelectual negra na atuação profissional na UFSB me fez compreender, na prática, que pensar políticas de ações afirmativas no ensino superior precisa necessariamente implicar mudança na concepção curricular, compreendendo o currículo não como um percurso linear, em que determinados conhecimentos/saberes vão se sobrepondo a outros em direção limitada porque já preestabelecida por quem o pensou, mas como uma seleção de percursos pluriepistêmicos a serem trilhados pelos estudantes, de acordo com os interesses existenciais e profissionais de cada um deles.

É nesse contexto de encruzilhada de saberes da organização curricular dos cursos de primeiro ciclo da UFSB, sobretudo nas LI, que tenho ministrado componentes curriculares comprometidos tanto com epistemologias africanas quanto com uma perspectiva educacional antirracista, anti-sexista e crítica com relação às diferenças. Dessa forma, ter participado da proposição ou ministrado CC tais como Educação e Relações Étnico-Raciais; Estéticas Negrodescendentes; Estéticas dos Povos Originários das Américas; África, Diáspora e Culturas Afro-Brasileiras; Movimentos artísticos e linguísticos dos povos pré-colombianos e diaspóricos nas Américas; Corporalidades negrodescendentes no Brasil; Artes da grafia: escrevivências, inscrições de si e do outro; nas LI de Artes e Ciências Humanas, potencializa a perspectiva de que a educação antirracista não deve estar relegada às margens de uma arquitetura curricular eurocentrada. Ao contrário, deve compor um planejamento de currículo ${ }^{15}$ que seja, na superfície e no fundo, crítico

\footnotetext{
14 Os Complexos Integrados de Educação (CIEs), negociados com a SEC-BA desde 2015, passam a se configurar realidade em 2016, em três escolas que sediam Colégios Universitários nos municípios de Itabuna, Porto Seguro e Teixeira de Freitas. Podem ser compreendidos como conglomerados educativos concebidos enquanto território destinado ao desenvolvimento de uma relação sistêmica entre escola básica e ensino superior. Tais conglomerados incluem salas da rede de Colégios Universitários (CUNI) da UFSB, escolas integrais de tempo integral (ensino médio), centros noturnos de educação e espaços pensados para a circulação desierarquizada de estudantes da UFSB e das escolas de ensino médio, de professores da UFSB e de escolas de ensino médio, de profissionais da educação, intelectuais, artistas, cientistas, mestres tradicionais e indivíduos da comunidade mais ampla das escolas e da Universidade empenhados em práticas educativas e/ou em ações para formação de professores, tanto das escolas de ensino médio quanto dos licenciandos da Universidade.

${ }^{15}$ Conforme tem sido trabalhado nesse artigo, currículo é compreendido enquanto discurso, escolha de um percurso narrativo que significa também seleção política de determinadas subjetividades para que se construam caminhos possíveis de ensino-aprendizagem. Na visada proposta, ao se assumir que tais escolhas narrativas implicam apreensão crítica das relações coloniais de poder, a concepção de currículo trabalhada aqui remete às Teorias Pós-Críticas, na classificação proposta por Tomaz Tadeu da Silva (2013).
} 
ao eurocentrismo que tem caracterizado o espaço acadêmico brasileiro. A perspectiva decolonial da produção de saberes e práticas não se institui como um mero adendo de um currículo de direcionamento eurocêntrico, mas como parte de um todo que, por escolha teórico-metodológica, rompe com uma educação profissional docente de direcionamento único, linear, monocultural, em uma única palavra, epistemicida.

Para compreender como novas pedagogias se desenvolvem em um ensino superior pensado a partir de currículo descolonizador, mostra-se importante observar as ementas de alguns desses CC, no sentido de compreender como práticas pedagógicas decoloniais podem ser pensadas em uma organização curricular que se propõe intercultural e pluriepistêmica:

EMENTA CC África, diáspora e culturas afro-brasileiras; Diáspora africana; Rota atlântica entre Brasil, África e as Américas; Dispersão, (re)criação e resistência cultural. Expansão mercantil e escravismo colonial no continente africano; Visões sobre África e "Áfricas"; Territórios, espaços e práticas negras no Brasil; Dilemas contemporâneos do continente africano; Racismo e resistência negra na África e no Brasil. (UF, 2016, p. 60)

O CC África, diáspora e culturas afro-brasileiras, pertencente ao projeto pedagógico da LI em Ciências Humanas e Sociais tem sido, para grande parte dos professores em formação, o primeiro contato mais denso com estudos da diáspora africana, teorias decoloniais e com intelectuais negras/os brasileiras/os que, muitas vezes ignorados pelo campo acadêmico das Ciências Sociais, produzem estudos, teorias e narrativas histórico-sociais sobre a sociedade brasileira a partir das demandas de mudança paradigmática colocadas pela produção intelectual da diáspora africana e por movimentos sociais negros. Dessa forma, ao lecionar neste CC, para além da compreensão crítica do conceito de diáspora, com Stuart Hall, Goli Guerreiro, Beatriz Nascimento, Paul Gilroy, foi possível trabalhar também interpretações sobre a formação históricosocial do Brasil partindo de conceitos como "amefricanidade" e "pretuguês" de Lélia Gonzalez, das categorias de "racismo mascarado", "identidade negra e mestiçagem", "racismo à brasileira", "afroperspectividade", dos autores Abdias do Nascimento, Kabengele Munanga, Antônio Sérgio Guimarães e Renato Noguera, respectivamente. Além disso, foi possível articular trabalho de pesquisa sobre a produção de intelectuais negras/os brasileiras/os e da diáspora africana pouco lidos no meio acadêmico-universitário brasileiro. A descoberta de que há densa produção intelectual de mulheres e homens negros foi visível na fisionomia curiosa dos estudantes que, diante do que leram, identificaram-se também como produtores de conhecimentos e saberes legítimos no meio acadêmico. Mais do que um exercício de cognição, esse encontro com produção de conhecimentos/saberes intelectuais silenciados tem sido uma experiência de emancipação.

EMENTA CC Estéticas Negrodescendentes

Estudo das culturas africanas, diaspóricas e do negro no Brasil. Sistema de arte fundado em práticas culturais negrodescendentes no Brasil. Culturas negras, sistemas de arte ocidentais e autóctones - encontros/confrontos e desdobramentos artísticos. Leituras e releituras da historiografia produzida pelo eurocentrismo; dos Estudos Colonialistas aos Estudos Culturais. "Afrobrasilidade" como unidade cultural - da marginalização eurocêntrica à conjuntura política atual. Arte e cultura: alteridade nas relações entre as matrizes afrodescendentes e outras matrizes culturais presentes no Brasil. (UFSB, 2015, p. 80)

Já no CC Estéticas Negrodescendentes, que compõe o projeto pedagógico da LI em Artes e suas Tecnologias, optei por fazer um misto de trabalho teórico e de criação artística acerca da 
subalternidade estabelecida por estéticas racistas, bem como uma possibilidade de discussão radicalmente transformadora da decolonialidade no campo das artes, pela subversão semântica de máscaras opressoras - desde Fanon a Grada Kilomba — criadas pelo colonialismo e pelo racismo a ele inerente. Dessa forma, a proximidade com o trabalho intelectual e artístico da intelectual e artista performática Grada Kilomba, neste CC, tem sido central no processo de reconfiguração dos corpos artísticos que passam a se compreender africanizados, nas turmas de artes da UFSB.

A mesma lógica descentralizada de planejamento curricular tem proporcionado que estudantes de diferentes áreas das LI continuem a se encontrar, mesmo depois que o percurso curricular específico de cada um dos cursos se inicie, através dos CC do Núcleo Pedagógico, comuns às cinco Licenciaturas Interdisciplinares ${ }^{16}$. Ou seja, um percurso aberto tem proporcionado para docentes e discentes de diferentes áreas encontros não só no decorrer da Formação Geral, mas também no percurso formativo das LI, pelo eixo de componentes curriculares e do Estágio Supervisionado, que também propõe um percurso de diálogo entre as cinco LI. Tal encontro acaba por mudar concepções educacionais de todos os envolvidos nessa formação inicial docente em nível de graduação. Nesse núcleo curricular destaca-se, na discussão da diferença racial, o CC Educação e Relações Étnico-raciais, cuja ementa merece ser lida:

\section{Educação e Relações Étnico-Raciais}

Plano nacional de implantação das diretrizes curriculares para as relações étnico raciais e história das culturas indígenas, africanas e afro-brasileira. Debate sobre as leis 10639/2003 e 11645/2008; políticas públicas e educação. (UFSB, 2016, p. 48)

Nesse componente curricular aberto a todas as LI, tem sido possível não só discutir parâmetros teórico-metodológicos que balizam políticas públicas de combate ao racismo epistêmico, por meio da contextualização sócio-histórica da legislação e das diretrizes curriculares para o ensino de história e cultura afro-brasileira, mas também levar os estudantes a conhecer pedagogias que se abrem para princípios civilizatórios africanos no Brasil e na diáspora, como a pedagoginga de Allan da Rosa (2013), a pretagogia de Sandra Haydée Petit (2015), as pedagogias de terreiro, na perspectiva de Vanda Machado (2013) e Marialda Silveira (2004), a ética afroperspectivista de Renato Noguera (2012), entre outras pedagogias e epistemologias afropluriversadas ou, como ultimamente tenho chamado, pedagogias da escrevivência.

\section{CONCLUINDO PARA ABRIR CAMINHOS}

Estar em Mpámbu a Niila (Bombonjira), ou numa encruzilhada, pode ser estar num ponto grande, alto e de auto poder, pois é estar no ponto dos sete movimentos de um ser

(Valdina Pinto, Makota Zimewaanga)

O que se quis demonstrar nesse artigo é que, para além da presença de componentes curriculares de perspectiva decolonial, houve um esforço epistemológico de se repensar a arquitetura curricular da formação docente na UFSB a partir de uma experiência de descentralização da lógica eurocêntrica, colonial, racista e sexista. Certamente, adequações e

${ }^{16}$ Os componentes do Núcleo Comum da Educação são Educação e Relações Étnico-Raciais; Bases Epistemológicas da Educação; Políticas Públicas Educacionais e Gestão Escolar; Educação Ambiental e Sustentabilidade; Educação e Direitos Humanos; Educação, Gênero e Diversidade Sexual; Educação Inclusiva; Libras. 
reajustes a essa organização do currículo farão parte da história dessa instituição federal de ensino superior. Por isso mesmo, houve aqui um empenho crítico para se contar parte dessa história universitária pela perspectiva de uma intelectual negra.

Há ainda muito a ser investigado sobre a arquitetura curricular da formação docente na UFSB no que tange à proposta emancipatória de se (re)pensar o currículo do ensino superior. Por ora, essa tentativa de uma curta autoetnografia, no sentido proposto por Daniela Versiani (2005), estabelece (re)memoração crítica da trajetória profissional recente de uma professora universitária negra brasileira que, partindo da própria atuação em universidade pública, se recoloca no campo da educação em perspectiva descolonizadora. Dessa forma, narrar-me profissionalmente em primeira pessoa me inscreve em rede com a escrita intelectual de mulheres negras que escolheram o exercício da crítica para compreender as contradições da tessitura social brasileira, marcadamente autoritária, de mentalidade colonial, profundamente desigual e violenta com os segmentos populacionais negros e indígenas, sobretudo dentro das instituições responsáveis por produzir e (re)produzir conhecimentos/saberes. Essa opção de me narrar em primeira pessoa também aponta para o direcionamento recente que tenho dado à minha vida acadêmica, em termos de ensino, pesquisa, extensão e criação, acabando por desenvolver práticas, sob o enfoque eurocêntrico do intelectual hegemônico, as quais (des)ensinam o olhar, os corpos, as maneiras de se fazer educação e arte.

Aventurar-me nesse exercício de escrita significou também construir reflexão crítica acerca de organização curricular que se quer descolonizadora e de práticas educacionais emancipatórias, apostando em formato de graduação docente que recompõe a trajetória vivente e profissional do educador, pela proposição de percursos curriculares ainda pouco usuais no sistema público de ensino no Brasil.

Por fim, é importante sinalizar o uso de encruzilhada não só como fundamento da escolha de caminhos na cultura nagô, mas sobretudo como metáfora do encontro desierarquizado de saberes diversos, privilegiado pela arquitetatura curricular das LI na UFSB. Assim, se iniciei esse artigo chamando Exu para abrir a fala, fecho esse exercício de escrevivência intelectual com ele também, abrindo caminhos para a produção de saberes e práticas decoloniais que, a partir do lugar complexo das encruzilhadas, buscam experimentar formas (afro)pluriversais de trabalhar a formação docente na universidade pública brasileira. Por isso, a ele também termino saudando: Laroyê!!

\section{REFERÊNCIAS}

ARROYO, Miguel G. Outros sujeitos, outras pedagogias. Petrópolis, Rio de Janeiro: Vozes, 2014.

CARNEIRO, Sueli. A construção do outro como não-ser como fundamento do ser. 2005. Tese (Doutorado em Educação) - Faculdade de Educação, Universidade de São Paulo, São Paulo, 2005.

EVARISTO, Conceição. Da grafia-desenho de minha mãe, um dos lugares de nascimento de minha escrita. In: ALEXANDRE, Marco Antônio (org.). Representações performáticas brasileiras: teorias, práticas e suas interfaces. Belo Horizonte, Mazza Ed., 2007, p. 16-21.

GOMES, Nilma Lino. O movimento negro educador: saberes construídos nas lutas por emancipação. Petrópolis, Rio de Janeiro: Vozes, 2017.

GOMES, Nilma Lino. Relações étnico-raciais, educação e descolonização dos currículos. Currículo sem Fronteiras, v. 12, n. 1, jan./abr. 2012, p. 98-109. 
GOMES, Nilma Lino. Intelectuais negros e produção do conhecimento: algumas reflexões sobre a sociedade brasileira. In: SANTOS, Boaventura de Sousa; MENESES, Maria Paula (orgs.). Epistemologias do Sul. São Paulo: Cortez, 2011.

MACHADO, Vanda. Pele cor da noite. Salvador: EDUFBA, 2013.

MUNANGA, Kabengele. Rediscutindo a mestiçagem no Brasil: identidade nacional versus identidade negra. Belo Horizonte: Autêntica, 2004.

NOGUERA, Renato. Ubuntu como modo de existir: elementos gerais para uma ética afroperspectivista. Revista da ABPN. v. 3, n. 6, nov. 2011-fev. 2012, p. 147-150.

NÓVOA, António. Firmar a profissão como professor, afirmar a profissão docente. Cadernos de Pesquisa, n. 166, v. 47, out./dez. 2017, p. 1106-1133.

PETIT, Sandra Haydée. Pretagogia: pertencimento, corpo-dança afroancestral e tradição oral africana na formação de professoras e professores. Contribuições do legado africano para a implementação da Lei n. 10.639/03. Fortaleza: EdUECE, 2015.

ROSA, Allan da. Pedagoginga, autonomia e mocambagem. Rio de Janeiro: Aeroplano, 2013.

SANTOS, Boaventura de Sousa; MENESES, Maria Paula (orgs.). Epistemologias do Sul. São Paulo: Cortez, 2010.

SANTOS, Boaventura de Sousa. Conbecimento prudente para uma vida decente: um discurso sobre as ciências revisitado. São Paulo: Cortez, 2006.

SILVA, Tomaz Tadeu. Documentos de identidade: uma introdução às teorias do currículo. Belo Horizonte: Autêntica, 2013.

SILVEIRA, Marialda Jovita. Educação pelo silêncio: o feitiço da linguagem pelo candomblé. Ilhéus, Bahia: Editus, 2004.

THIESEN, Juares da Silva. A interdisciplinaridade como um movimento articulador no processo de ensino-aprendizagem. Revista Brasileira de Educação, n. 39, v. 13, set./dez. 2008, p. 545-554.

UFSB. Plano Orientador. Itabuna, Porto Seguro, Teixeira de Freitas: UFSB, 2014.

UFSB. Projeto Pedagógico de Curso da Licenciatura Interdisciplinar em Ciências Humanas e Sociais e suas Tecnologias. Itabuna, Porto Seguro, Teixeira de Freitas: UFSB, 2015.

UFSB. Projeto Pedagógico de Curso da Licenciatura Interdisciplinar em Artes e suas Tecnologias. Itabuna, Porto Seguro, Teixeira de Freitas: UFSB, 2015.

VAN ACKER, Maria Teresa Vianna; GOMES, Marineide de Oliveira. Ateliê biográfico de projeto na formação de professores: uma perspectiva emancipatória. Revista Educação Pública. Cuiabá, n. 48, v. 22, jan./abr. 2013, p. 29-42.

VERSIANI, Daniela Beccaccia. Autoetnografias: conceitos alternativos em construção. Rio de Janeiro: 7 Letras, 2005.

Submetido em marco de 2020 Aprovado em julbo de 2020 


\section{Informações da autora}

Fabiana de Lima Peixoto

Professora Adjunta da Universidade Federal do Sul da Bahia (UFSB), Campus Jorge Amado, Itabuna-BA. Doutorado em Estudos Étnicos e Africanos pela Universidade Federal da Bahia.

E-mail: fabianalimaufsb@gmail.com

ORCID: https://orcid.org/0000-0002-2865-8299

Link Lattes: http://lattes.cnpq.br/7006970600909207 